Document downloaded from:

http://hdl.handle.net/10251/97801

This paper must be cited as:

Valencia-Sullca, CE.; Jiménez Serrallé, M.; Jiménez Marco, A.; Atarés Huerta, LM.; Vargas, M.; Chiralt A. (2016). Influence of liposome encapsulated essential

oils on properties of chitosan films. Polymer International (Online). 65(8):979-987. doi:10.1002/pi.5143

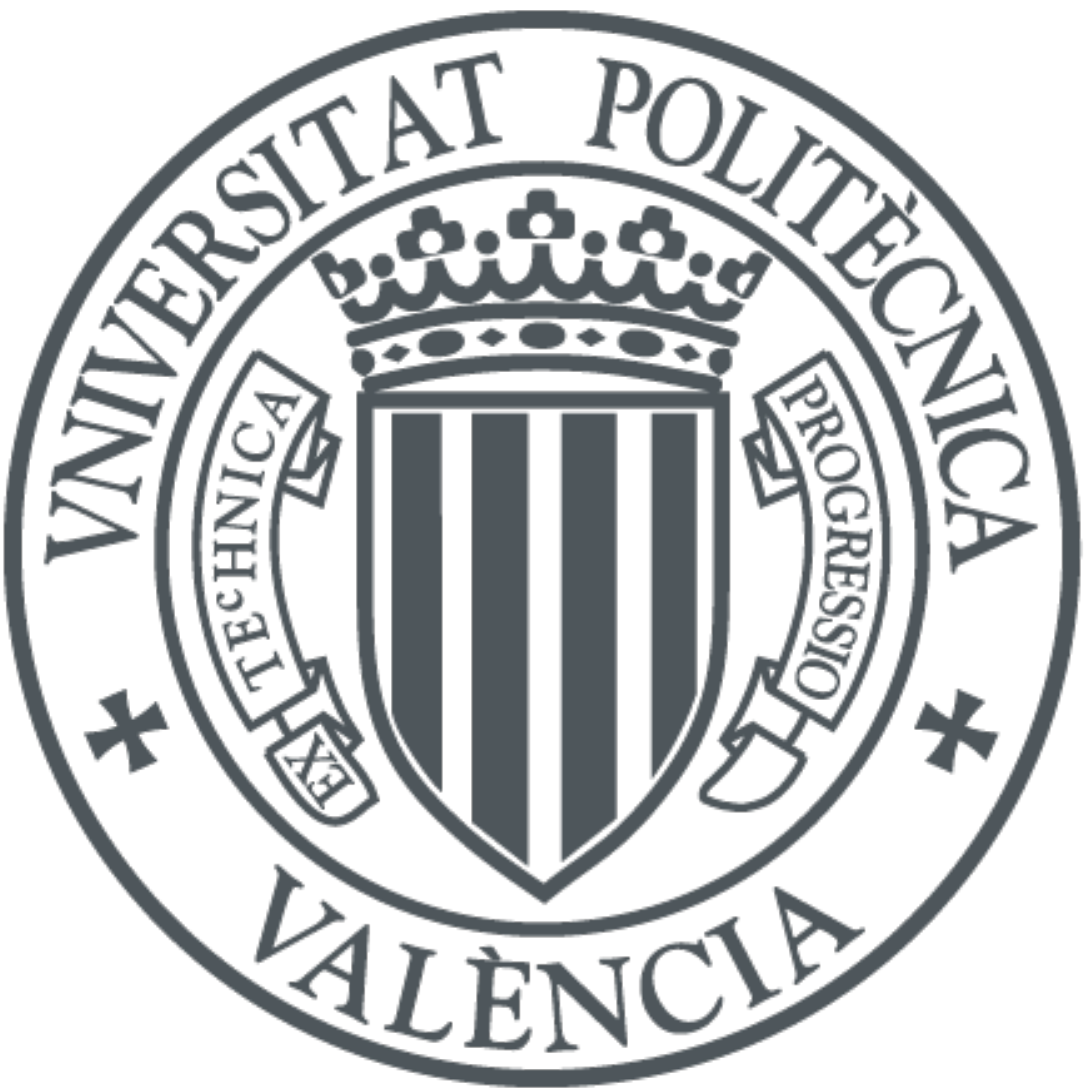

The final publication is available at

http://doi.org/10.1002/pi.5143

Copyright John Wiley \& Sons

Additional Information 


\section{INFLUENCE OF LIPOSOME ENCAPSULATED ESSENTIAL OILS ON PROPERTIES OF CHITOSAN FILMS}

Cristina Valencia-Sullca; Miriam Jiménez; Alberto Jiménez; Lorena Atarés; Maria Vargas*; Amparo Chiralt Instituto de Ingeniería de Alimentos para el Desarrollo, Departamento de Tecnología de Alimentos, Universitat Politècnica de València, Camino de Vera s/n, 46022 Valencia, Spain

\section{Abstract}

The effect of the encapsulation of eugenol and cinnamon leaf essential oil (CLEO) in lecithin liposomes on the losses of these compounds during the chitosan film formation process by casting was evaluated. Film-forming dispersions and films with eugenol or CLEO (either free or encapsulated) were obtained and characterized. The content of eugenol in active films was quantified by means of solvent extraction and GC analysis. The encapsulation of eugenol or CLEO in lecithin liposomes led to the films retaining $40-50 \%$ of the incorporated eugenol, whereas only $1-2 \%$ was retained when eugenol was incorporated by direct emulsification. Films with liposomes exhibited a lamellar microstructure which improved film extensibility and increased water vapour barrier capacity with respect to those with free emulsified compounds. Liposomes also modified the optical properties of the films, reducing their gloss, increasing colour saturation and making them redder in colour. The encapsulation of volatile active compounds in liposomes appears to be a good strategy for obtaining antimicrobial films with essential oils.

Key Words: chitosan, eugenol, liposome, lecithin, cinnamon leaf essential oil, encapsulation. 


\section{Introduction}

Biopolymer films containing antioxidant/antimicrobial compounds, which can be useful for the development of active packaging materials, are of great interest for the purposes of food quality and safety preservation and as a means of extending shelf-life. In this sense, the use of biodegradable polymers is advisable in order to reduce the environmentally harmful effects caused by the use of synthetic polymer-based packages and in order to limit the exploitation of constantly shrinking oil reserves. ${ }^{[1]}$

Chitosan $(\mathrm{CH})$ is a cationic, non-toxic, biodegradable polysaccharide, compatible with other biopolymers, which film-forming properties have been extensively studied. ${ }^{[2]}$ This natural biopolymer can be obtained from the deacetylation of the chitin present in crustacean exoskeletons, and it has potential applications in the food industry on the basis of its described characteristics and its antimicrobial properties. $\mathrm{CH}$ films exhibit good mechanical and structural properties and constitute a good barrier to gases and aromas.

The incorporation of essential oils (EO) into the chitosan matrix could improve its functionality for food preservation purposes, since antimicrobial properties would be enhanced at the same time as the water barrier capacity of the films was improved, in line with the increase in the films' hydrophobic fraction. ${ }^{[3]}$ Particularly, cinnamon leaf essential oil (CLEO) and its main compound, eugenol, have been described as antibacterial and antifungal agents at

relatively low concentrations in previous studies. ${ }^{[4-6]}$ The minimal inhibitory concentration (MIC) of eugenol against Listeria monocytogenes and 
Escherichia coli is $1.5 \mathrm{~g} / \mathrm{L}$ and $1.0 \mathrm{~g} / \mathrm{L}$, respectively. ${ }^{[7]}$ Eugenol has been recognized as safe by the FDA (Food and Drug Administration) ${ }^{[8]}$ and approved by the European Union as a safe savoring agent for foods. ${ }^{[9]}$

Different essential oils have been widely used in the formulation of active biodegradable films, ${ }^{[10]}$ but, on top of their potential sensory impact on the coated or packaged product, the losses of these volatile compounds during film preparation represent an added problem. ${ }^{[11,12]}$ EOs have been incorporated into hydrophilic biopolymer films by emulsification in the aqueous film-forming dispersion of the polymer before film formation, which was performed by casting technique. ${ }^{[13,14]}$ Nevertheless, during the film drying step, oil droplets flocculate, coalesce and cream to the top of the drying film, where oil components volatilize together with water at a lower temperature than their boiling point (steam distillation). ${ }^{[3]}$

The encapsulation of essential oil compounds before film preparation can mitigate both the losses and the sensory impact of EOs, also contributing to modulate the release kinetics of actives into the product. In this sense, the use of liposomes or nanoliposomes, ${ }^{[15]}$ which can act as carrier systems of a wide range of compounds, represent an interesting alternative. Nevertheless, the presence of these lipid structures in the film matrix may affect the functional (mechanical, barrier or optical) film properties as packaging material.

The aim of this study was to assess the effect of the encapsulation of eugenol (Eu) and cinnamon leaf essential oil (CLEO) within lecithin nanoliposomes on their retention in chitosan films during film formation, as compared to free compounds. Likewise, the effects of the incorporation of nanoencapsulated 
compounds on the film structur, physical properties and antimicrobial activity, were analysed, in comparison with the free-form incorporation.

\section{Materials and methods}

\subsection{Materials}

High molecular weight chitosan (practical grade, $>75 \%$ deacetylation degree, Batch MKBP1333V, supplied by Sigma-Aldrich Chemie, Steinheim, Germany) was used as film-forming polymer. Glacial acetic acid, magnesium nitrate-6hydrate and diethyl ether (ethanol stabilized) were supplied by Panreac Química SLU (Castellar del Vallés, Barcelona, Spain). For nanoliposome formulation, non-GMO sunflower seed lecithin with $20 \%$ phosphatidylcholine, supplied by Lipoid H2O (Lipoid gmbh, Ludwigshafen, Germany) was used. Cinnamon leaf oil (Herbes de Molí, Coop. V., Benimarfull, Alicante, Spain) and its main component, eugenol (Sigma Aldrich Química S.L., Madrid, Spain) were used as antimicrobial agents. Sephadex ${ }^{R}$ G50 and anhydrous sodium sulphate were purchased from Sigma Aldrich Química S.L., (Madrid, Spain) and Triton X100 from Carl Roth GmbH (Karlsruhe, Germany).

\subsection{Preparation of nanoliposome dispersions}

Preparation of nanoliposome dispersions was carried out according to a previously described method. ${ }^{[15,16]}$ Lecithin was dispersed in distilled water (5 wt $\%$ and stirred for 4 hours at $700 \mathrm{rpm}$. Eugenol or CLEO at $5 \mathrm{wt} \%$ was 
incorporated to the lecithin dispersion and afterwards three different liposome samples were obtained (Lec, Lec-Eu and Lec-CLEO) by sonication at $20 \mathrm{kHz}$ for 10 minutes with one-second pulses. The ultrasound probe was placed in the center of the sample.

The encapsulation efficiency in the nanoliposome dispersions was determined. To this end, Sephadex ${ }^{\circledR}$ gel filtration was conducted. Sephadex G50 (0.5g) was added to swell in deionized water $(10 \mathrm{~mL})$ for $6 \mathrm{~h}$. A layer of about $5 \mathrm{~cm}$ of gel was formed. In order to eliminate the excess water, the column was centrifuged at 1,500rpm for $7 \mathrm{~min}$ (Medifriger-BL, P-Selecta, Barcelona, Spain). Finally, $1 \mathrm{ml}$ Lec-Eu or Lec-CIEO liposome sample was added on the top of the column and the centrifugation was repeated. The gel-filtered liposomes were destabilized by the addition of $3 \mathrm{~mL}$ of $0.15 \mathrm{w} / \mathrm{v} \%$ Triton $\mathrm{X} 100$ followed by vortexing. The active compounds were recovered by extraction with $2 \mathrm{ml}$ diethylether and centrifugation at $2000 \mathrm{rpm}$ for $10 \mathrm{~min}$, which were repeated three times. The extract was dehydrated with anhydrous sodium sulphate, afterwards filtered and dry nitrogen flow was used to eliminate the remaining solvent. Finally, the extract was stored in a desiccator with silicagel, and the mass of encapsulated active compound was determined. The results of encapsulation efficiency were expressed as the ratio between the encapsulated and the incorporated active compound.

\subsection{Preparation of chitosan films with active compounds}

A solution of $1 \%$ chitosan $(\mathrm{w} / \mathrm{w})$ was prepared in a $1 \%(\mathrm{v} / \mathrm{w})$ acetic acid solution. This was stirred at room temperature for 24 hours and then filtered with a sieve 
$(120 \mu \mathrm{m}$ pore size). The active compounds (Eu and CLEO) were incorporated in two different forms: either encapsulated in lecithin liposomes or by direct emulsification. For this purpose, $0.5 \mathrm{~g}$ of active compound (Eu or CLEO), either as free form or as lecithin liposomes (in this case $1.0 \mathrm{~g}$ of the active liposome dispersion) were added to $90 \mathrm{~g}$ of the chitosan solution. In this way, a 26 or 36 wt \% of Eu or CLEO in the film dry solids was obtained for films with and without lecithin, respectively. This percentage was selected to overcome the values of the minimal inhibitory concentration (MIC) of actives against some typical patogens or food spoilage microorganisms ${ }^{[7,17]}$ according to previuos studies with chitosan films containg CLEO.[3] A control film with lecithin liposomes without active compound was also obtained by incorporating to $0.5 \mathrm{~g}$ of lecithin as liposome dispersion (26 wt \% of the film solids).

Film-forming dispersions with liposomes were kept under stirring for 2 hours before casting, while those containing free active compounds were homogenized in an Ultraturrax homogenizer (Yellow Line Model DI 25 basic, IKA, Germany) at 13,500 rpm for 4 minutes.

Thus, 6 film-forming dispersions (FFD) were obtained: pure chitosan $(\mathrm{CH})$, control with lecithin $(\mathrm{CH} / \mathrm{Lec})$, films with eugenol or cinnamon leaf essential oil, non-encapsulated $(\mathrm{CH} / \mathrm{Eu}$ and $\mathrm{CH} / \mathrm{CLEO})$ and encapsulated in lecithin $(\mathrm{CH} / \mathrm{Lec}-$ $\mathrm{Eu}$ and $\mathrm{CH} / \mathrm{Lec}$-CLEO). The FFDs were poured into $150 \mathrm{~mm}$ diameter Teflon plates ( $1 \mathrm{~g}$ of solids per plate). The films were obtained by drying at $25^{\circ} \mathrm{C}$ and $45 \%$ relative humidity.

Prior to characterization, the films were conditioned for one week at 53\% relative humidity, using saturated solutions of $\mathrm{Mg}\left(\mathrm{NO}_{3}\right)_{2}$, at $25^{\circ} \mathrm{C}$. 


\subsection{Characterization of nanoliposome and film-forming dispersions}

Both nanoliposome and film-forming dispersions (ND and FFD) were characterized in triplicate as to their density, $\zeta$-potential and particle size. The density of the different samples was measured using the pycnometer method. In order to determine the diameter (z-average) and $\zeta$-potential of nanoliposomes, the samples were diluted in distilled water (1:100) and measured at $25^{\circ} \mathrm{C}$ in a Zetasizer Nano-Z device (Nano series model Zen 2600, Malvern Instruments, Worcestershire, United Kingdom). This equipment measures the electrophoretic mobility through light scattering caused by the dispersed particles, and the $\zeta$-potential is determined using the Smoluchowsky model. All of the samples were measured in triplicate.

\subsection{Film characterization}

\subsubsection{Eugenol retention in the films}

Retention of the EO compounds in the films during the film formation was determined through the total eugenol content in the films analysed by GC. To this end, $0.3 \mathrm{~g}$ film samples were extracted with $10 \mathrm{~mL}$ of diethyl ether for 24 hours. This time was set after preliminary tests as the total extraction time. $2 \mu \mathrm{l}$ of extracts were injected (injection temperature, $50^{\circ} \mathrm{C}$ ) in a gas chromatograph (Hewlett Packard 6890 FID GC System) with flame ionization detector (GC-FID) using a DB-5 column (30 mm x $0.32 \mathrm{~mm}$ of internal diameter); $0.25 \mu \mathrm{m}$ film thickness (V J \& Scientifics, Agilent, Palo Alto, USA). Helium (1 mL / min) was used as carrier gas. The heating schedule was: heating at $5^{\circ} \mathrm{C} / \mathrm{min}$ from $50{ }^{\circ} \mathrm{C}$ to $130^{\circ} \mathrm{C}$, and holding at $130^{\circ} \mathrm{C}$ for $5 \mathrm{~min}$, followed by heating at $10^{\circ} \mathrm{C} / \mathrm{min}$ up to $200^{\circ} \mathrm{C} .{ }^{[18]}$ For the purposes of eugenol quantification, a calibration curve 
using eugenol solutions in ethyl ether in the range of $50-2000 \mathrm{ppm}$ was obtained. The wt \% of Eu in CLEO was also determined through GC analysis under the same conditions. The amount of retained $\mathrm{Eu}$ in the films was obtained. For films contining CLEO, the quantified Eu peak in each extract and the corresponding Eu percentage in the CLEO were taken into account. Results were expressed as the percentage of retained eugenol in the film (mass of extracted compound/mass of incorporated compound).

\subsubsection{Thickness}

Film thickness was measured using a digital electronic micrometer (Palmer model, Comecta S.A., Barcelona, Spain) to the nearest $0.0005 \mathrm{~mm}$. Six measurements per sample were taken performed in random positions, and the results were used to analyze the tensile and barrier properties of the films.

\subsubsection{Tensile properties}

The tensile behaviour of films was tested by using a universal test Machine (TA.XTplus model, Stable Micro Systems, Haslemere, England). The elastic modulus (EM), tensile strength (TS) and elongation at fracture (\%E) were determined following ASTM standard method D882. ${ }^{[19]}$ These parameters were obtained from the stress-Henky strain curves calculated from the force-distance data.

Equilibrated film strips (25 mm wide, $100 \mathrm{~mm}$ long) were mounted in the filmextension grips of the testing machine and stretched at $50 \mathrm{~mm} \mathrm{~min}{ }^{-1}$ until breaking. At least eight replicates were obtained per formulation. 


\subsubsection{Moisture content, water vapor permeability and solubility}

The moisture content of the films was determined using a gravimetric method. Firstly, the film samples were dried in a convection oven at $60^{\circ} \mathrm{C}$ for $24 \mathrm{~h}$, and then in a vacuum oven (Vacioterm-T, JP-selecta S.A., Barcelona, Spain) at 60 ${ }^{\circ} \mathrm{C}$ and 0.8 bar for $48 \mathrm{~h}$. Finally, in order to remove the residual moisture, the samples were conditioned in a dessicator with $\mathrm{P}_{2} \mathrm{O}_{5}$ till constant weight. The results were expressed as $\mathrm{g}$ of water per $100 \mathrm{~g}$ of dry film.

The WVP of the films was determined by using the ASTM E96-95 gravimetric method, ${ }^{[20]}$ taking into account the modification proposed by other authors. ${ }^{[21]}$ Films were selected based on the lack of physical defects, such as cracks, bubbles, or pinholes. Six samples per formulation were cut, and distilled water was placed in Payne permeability cups $(3.5 \mathrm{~cm}$ diameter, Elcometer SPRL, Hermelle /s Argenteau, Belgium) to expose the film to $100 \% \mathrm{RH}$ on one side. Once the films were secured, each cup was placed in a relative humidity equilibrated cabinet at $25^{\circ} \mathrm{C}$, with a fan placed on the top of the cup in order to reduce resistance to water vapor transport. The $\mathrm{RH}$ of the cabinets (53\%) was held constant using oversaturated solutions of magnesium nitrate-6-hydrate. The cups were weighed every $1.5 \mathrm{~h}$ for $24 \mathrm{~h}$ with an analytical scales (ME36S Sartorius, Alemania - $0.0001 \mathrm{~g}$ ). Once the steady state had been reached, water vapor transmission rate was determined from the slope obtained from the regression analysis of weight loss data versus time, divided by the film area. WVP was obtained taking into account the average film thickness in each case. The equation proposed by other studies ${ }^{[21]}$ was used to correct the effect of concentration gradients established in the stagnant air gap inside the cup. 
In order to determine the film solubility, film samples were immersed in double distilled water (film: water mass ratio 1:200), and kept at $25{ }^{\circ} \mathrm{C}$ for 24 hours. After this, the films were dried in a convection oven (JP Selecta, SA Barcelona, Spain) at $60^{\circ} \mathrm{C}$ for 24 hours. Finally, the film samples were dried in a vacuum oven at $60{ }^{\circ} \mathrm{C}$ to constant mass. Solubility was expressed as the percentual loss of the dry solids of the film by water solution, as rrefered to the initial mass of the dry film.

\subsubsection{Optical properties}

The opacity of the films was determined by applying the Kubelka-Munk theory for multiple scattering. ${ }^{[22,23]}$ A spectrocolorimeter (CM-3600d Minolta CO., Tokyo) was used to obtain the reflection spectra of the films on a white $(R)$ and a black $\left(R_{0}\right)$ background between 400 and $700 \mathrm{~nm}$, as well as the spectrum of the white background used $\left(\mathrm{R}_{\mathrm{g}}\right)$. From these spectra, the internal transmittance ( $T_{i}$, a transparency indicator) and $R_{\infty}$ (the reflectance of an infinitely thick film), were calculated using equations (1) to (4). Three measurements were taken on each film and three films were considered per formulation. From $R_{\infty}$ spectra, the CIEL* $a^{*} b^{*}$ color coordinates were determined using the $10^{\circ}$ observer and the D65 illuminant as reference. ${ }^{[23]}$ Moreover, hue $\left(h_{a b}{ }^{*}\right)$ and chroma $\left(C_{a b}{ }^{*}\right)$ were calculated by using equations (5) and (6).

$$
\begin{aligned}
& T i=\sqrt{\left(a+R_{0}\right)^{2}-b^{2}} \\
& \mathrm{a}=\frac{1}{2} \cdot\left(\mathrm{R}+\frac{\mathrm{R}_{0}-\mathrm{R}+\mathrm{R}_{\mathrm{g}}}{\mathrm{R}_{0} \mathrm{R}_{\mathrm{g}}}\right)
\end{aligned}
$$




$$
\begin{aligned}
& \mathrm{b}=\left(\mathrm{a}^{2}-1\right)^{1 / 2} \\
& \mathrm{R}_{\infty}=\mathrm{a}-\mathrm{b} \\
& h_{a b}^{*}=\operatorname{arctg}\left(\frac{b^{*}}{a^{*}}\right)(5) \\
& C_{a b}^{*}=\sqrt{\mathrm{a}^{* 2}+\mathrm{b}^{* 2}}(6)
\end{aligned}
$$

Gloss was measured using a flat surface gloss meter Multi Gloss 268 (Minolta, Langenhagen, Germany) at a $60^{\circ}$ angle of incidence according to ASTM D523 standard. ${ }^{[24]}$ The film samples were placed on a matte black surface, and nine measurements per formulation were taken on the side of the film that was exposed to the atmosphere during drying.

\subsubsection{Scanning electron microscopy (SEM)}

The microstructural analysis of the cross-sections and surface images of the films was carried out using a scanning electron microscope (model JEOL JSM5410, Japan). The film samples were maintained in desiccators with $\mathrm{P}_{2} \mathrm{O}_{5}$ in order to eliminate film moisture. Film pieces $\left(0.5 \mathrm{~cm}^{2}\right.$ approximately) were cryofractured by immersion in liquid nitrogen and mounted on copper stubs. After gold coating, the samples were observed using an accelerating voltage of $10 \mathrm{kV}$.

\subsubsection{Thermogravimetric analysis (TGA)}

The thermal stability of the films was studied by TGA using a Mettler-Toledo thermobalance (model TGA / SDTA 851e, Schwarzenbach, Switzerland). Crushed film samples $(3 \mathrm{mg})$ were gradually heated at $7{ }^{\circ} \mathrm{C} / \mathrm{min}$ from room 
temperature to $600{ }^{\circ} \mathrm{C}$ under nitrogen flow (50 mL / min). The onset temperature $\left(T_{0}\right)$ and maximum degradation rate temperature $\left(T_{\max }\right)$ of the films were registered in two replicates per formulation.

\subsection{Antimicrobial activity}

Listeria innocua (CECT 910) and Escherichia coli (CECT 101) were supplied by the Spanish Type Culture Collection (CECT, Burjassot, Spain). These bacterial cultures were regenerated (from a culture stored at $-25{ }^{\circ} \mathrm{C}$ ) by transferring a loopful into $10 \mathrm{~mL}$ of Tryptone Soy Broth (TSB, Scharlab, Barcelona, Spain) and incubating at $37^{\circ} \mathrm{C}$ for 24 hours. From this culture, a $10 \mu \mathrm{L}$ aliquot was again transferred into $10 \mathrm{~mL}$ of TSB and grown at $37^{\circ} \mathrm{C}$ for 24 hours more in order to obtain a culture in exponential phase of growth. Afterwards, this bacterial culture was appropriately diluted in TSB tubes to get a target inoculum of $10^{5}$ $\mathrm{CFU} / \mathrm{mL}$. Circular samples of $55 \mathrm{~mm}$ in diameter, obtained from the different types of film formulations were placed on inoculated Tryptose Soya Agar plates (solid medium test) and in Tryptose Soya Agar tubes (liquid medium test). Inoculated tubes and plates without film were used as control samples. Immediately after the inoculation and after 6 days at $10^{\circ} \mathrm{C}$ the microbial counts on Tryptone Soy Agar (TSA, Scharlab, Barcelona, Spain) plates were determined. In the liquid medium tests (broth tubes), serial dilutions were made and poured onto TSA dishes which were incubated for 24 hours at $37^{\circ} \mathrm{C}$. For the solid medium tests (agar plates) the dishes content was removed aseptically and placed in a sterile plastic bag with $90 \mathrm{~mL}$ of Buffered Peptone Water. The bags were homogenized with a Stomacher (Interscience BagMixer Stomacher $400 \mathrm{~W}$ Homogenizer, France). Serial dilutions were made and then poured into 
TSA Petri dishes. Samples were incubated at $37^{\circ} \mathrm{C}$ for 24 hours before colonies were counted. All the tests were run in triplicate.

\subsection{Statistical analysis}

The statistical analysis of the data was performed through an analysis of variance (ANOVA) using Statgraphics Centurion XVI.II. Fisher's least significant difference (LSD) procedure was used.

\section{Results and discussion}

\subsection{Properties of nanoliposome and film-forming dispersions}

The encapsulation degree in the nanoliposome dispersions was $98.2 \pm 0.7 \%$, without significant differences for the type of active (Eu or CLEO). So, the nonencapsulated oil ratio was negligible in both cases, which indicates that the direct incorporation of ND into the FFD is an adequate method for the formulation of films with nanoliposomes.

The density and $\zeta$-potential values of ND and FFD are shown in Table 1. No significant differences were found for the density values of nanoliposome dispersions with essential oil or with eugenol. The lecithin nanoliposomes exhibited negative $\zeta$-potential values, with a greater negative charge when the active compounds were incorporated. The FFD had high positive values of $\zeta$ potential due to the charges of the chitosan chain with protonated amine groups

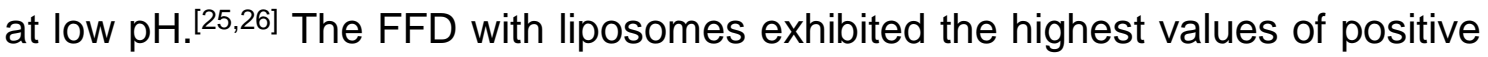
$\zeta$-potential, without no significant differences between them, which indicates that the positively charged chitosan molecules adsorbed on the negatively charged nanoliposomes, thus giving rise to a reversed surface charge and greater 
values of $\zeta$-potential than pure $\mathrm{CH}$ dispersions and those containing emulsified compounds. On the other hand, the addition of emulsified active compounds also promoted the increase in $\zeta$-potential values, which indicates that $\mathrm{CH}$ molecules also adsorb on the droplet surface, but to a lesser extent than on negatively charged liposomes, due to the electrostatic interactions with the positively charged chains. $\mathrm{CH}$ adsorption will contribute to the stability of the liposomes during the film drying, in which water loss can lead to phase transitions in the lipid structures, ${ }^{[27,28]}$ releasing the encapsulated material.

The size distribution of lipid particles dispersed in the film-forming emulsions affects the properties of the final film, such as water vapor permeability and mechanical properties. ${ }^{[29]}$ Figure 1 shows the particle size distribution in the obtained liposome dispersions, and the zeta average size values in the three nanoliposome dispersions, where significant differences can be seen $(p<0.05)$. Incorporating eugenol or essential oil to liposomes led to an increase in the size of the smaller particles, hence an increase in the average zeta size. Nevertheless, no notable differences were observed for size distributions of liposomes loaded with both components. Pure lecithin nanoliposomes had the smallest average size $(90.6 \mathrm{~nm})$ and the incorporation of the active compounds resulted in larger particles due to their incorporation in the liposome core. The size of lipid associations in an aqueous medium tends to increase as the hydrophobic nature of their molecules increases. ${ }^{[30,31]}$

\subsection{Film properties}

\subsubsection{Eugenol and essential oil retention}


Table 2 shows the amount of active compound extracted from the films, the nominal mass of active compound added to the film sample and the respective percentage retention (with respect to the initial amount) in each sample. The encapsulation of the active compounds in lecithin liposomes greatly reduced the loss of the active compounds during the film drying step, and $40-50 \%$ of the incorporated eugenol was retained in the film. This indicates the effectiveness of this strategy as a means of preventing the losses of volatile compounds during the film drying. The highest eugenol retention (51\%) was obtained from the films containing encapsulated cinnamon leaf oil, which may be due to the predominant loss of other, more volatile essential oil compounds during the drying step. On the other hand, in the films with non-encapsulated active compounds, eugenol losses reached $99 \%$ of the added amount, which implies a final content in the dried film of $0.6 \mathrm{wt} \%$ of the total solids. This amount is very low and suggests that a part of the active could be bonded to the polymer matrix and it was not extracted by the solvent. Nevertheless, the obtained results demonstrate the efficacy of liposome encapsulation to limit volatile losses during the film preparation process.

\subsubsection{Thickness and tensile properties}

Table 3 shows the thickness and tensile parameters of the films. The chitosan film thickness ranged between 33 and $49 \mu \mathrm{m}$, and it decreased when free essential oils were incorporated. This is coherent with the partial volatilization of the oils, involving an effective reduction in the amount of solids per area unit of the film. The addition of encapsulated compounds provoked an increase in the films' thickness with respect to pure chitosan in line with the lower losses of 
volatiles and a different microstructural arrangement of the film components as previously observed by other authors. ${ }^{[16]}$

The elastic modulus (EM), tensile strength (TS) and deformation at break (\%E) describe the tensile properties of the films, which are closely related to their structure. ${ }^{[32]}$ The EM significantly decreased subsequent to the addition of lecithin liposomes, both single and loaded with actives, which can be attributed to the interruptions in the polymer matrix introduced by lipid particles. This leads to a loss of network cohesion, as observed by other authors when studying different matrices. ${ }^{[30,31]}$ Adding non-encapsulated oils only caused a slight EM reduction, which can be explained by the lower lipid ratio and the arrangement of the lipid droplets in the film matrix. Whereas TS and \%E were not affected by the addition of non-encapsulated oils, the films with liposomes exhibited increased extensibility, with similar TS values to the $\mathrm{CH}$ control film. Pure chitosan films were mechanically stronger and less extensible than films with liposomes. This different behavior may be explained by the different structural arrangement of components, as commented on below.

\subsubsection{Moisture content, water vapor permeability and solubility}

Water vapor permeability (WVP) is a relevant property directly related to the usefulness of the film in food applications, and should be as low as possible to prevent the transfer of water. ${ }^{[33]}$ Table 4 shows the moisture content, water vapor permeability and solubility of the films. The equilibrium moisture content of the films decreased significantly when both free and encapsulated lipid compounds were added, since the proportion of active sites for water adsorption per unit dry mass decreases. ${ }^{[34]}$ Likewise, possible interactions between the chitosan chains and the active compounds could reduce the 
availability of the chitosan polar groups to form hydrophilic bonds with water molecules. ${ }^{[35]}$ As compared to the films with non-encapsulated active compounds, lecithin incorporation resulted in a significant WVP decrease. A different final amount of lipid in the films, as well as the differences in their structural arrangement, may explain their different effectiveness at reducing water vapor permeability. Film solubility in water was also significantly reduced by the addition of lipids (lecithin or EO compounds); the greater the total lipid content, the lower the solubility values, coherently with the increased hydrophobic character of the film. ${ }^{[36]}$

\subsubsection{Optical properties}

According to other studies, ${ }^{[23]}$ the transparency and brightness of the material are the most important optical properties with which to assess the direct impact on the appreciation of the color and appearance of a coated/packaged product. Table 4 shows the values of lightness $\left(L^{*}\right)$, chroma $\left(C^{*} a b\right)$, hue $\left(h^{*} a b\right)$ and gloss at $60^{\circ}$ of the different samples. Due to the typical color of lecithin, films with liposomes were darker, with a more saturated reddish color than the pure chitosan films. This effect was also previously observed in starch-sodium caseinate films with lecithin liposomes. ${ }^{[16]}$ The gloss was decreased by incorporating active compounds, especially in free form, which can be attributed to the increase in surface roughness associated with the creaming of lipids during drying, as previously observed for lipid containing films. ${ }^{[31,37]}$

Figure 2 shows the spectral distribution curves of $\mathrm{T}_{\mathrm{i}}$. The incorporation of free lipids, and particularly the incorporation of liposomes, reduced the $\mathrm{T}_{\mathrm{i}}$ of the films; in line with the presence of a dispersed phase in the matrix which 
enhances light scattering. In the case of liposomes, the absorbance of lecithin also contributes to lower the transmittance of the films.

\subsubsection{Microstructural properties}

A microstructural study of the films allows the arrangement of the components in the dry films to be observed, and correlates these observations with other functional-characteristics, such as the barrier, mechanical and optical properties. ${ }^{[38]}$ Figures 3 and 4 show the micrographs of the cross section and surface of the obtained films, respectively. The holes corresponding to eugenol or oil droplets in the cross section of the films can be seen when these are incorporated in free form $(\mathrm{CH} / \mathrm{Eu}, \mathrm{CH} / \mathrm{CLEO})$. On the surface of the films with these free compounds, some droplet footprint can also be observed, whereas the films with liposomes show a smoother surface. These holes were probably caused by the evaporation of the volatile compounds during the film drying or during SEM observation under high vacuum conditions. On the other hand, when active compounds are incorporated in liposome form, no visible drops can be seen in the structure whereas laminar formations can be observed, where void layers intercalate with polymer fibrous arrangements. This appearance suggests that lamellar liposomal lipid associations were formed during the film drying step, in line with the liotropic mesomorphism of lipid associations, [28] which would be inserted between the polymer layers producing a laminated structure. In this arrangement, eugenol or cinnamon essential oil would occupy the hydrophobic core of the laminar structures. $\mathrm{CH} / \mathrm{Lec}$ films also exhibited a laminar structure, but the separation between layers expands when there is eugenol or essential oil in the formulation. So, as the water content in the FFD is reduced during film drying, the micellar associations undergo phase 
transitions and lamellar structures tend to form, containing lipids at the hydrophobic core. ${ }^{[27]}$

This laminar structure explains the greater elongation capability of the films containing liposomes during the tensile test, especially those containing eugenol or essential oil, since the layers can easily slide during the test, hence allowing for a greater deformation before fracture. However, the weaker cohesive force between layers, as compared to that acting between polymer chains, would lead to softer films (less resistant to deformation) with lower elastic modulus, as shown in Table 3. Likewise, the formation of lipid layers perpendicular to the mass transport in the film, also explains the great reduction in the water vapour permeability and water solubility of the films when liposomes were added to the film formulation.

\subsubsection{Thermogravimetric analysis (TGA)}

Figure 5 shows the thermal degradation curves (derivative curve: DTGA) of chitosan films, where three stages can be observed. The first mass loss step below about $100^{\circ} \mathrm{C}$ is due to the evaporation of residual water from the films. The second step can either be attributed to the degradation/volatilization of low molecular weight fractions, such as volatile compounds and lecithin, or to the losses of some groups (such as $\mathrm{NH}_{2}$ ) from chitosan chains, and the third step is associated with the decomposition of polymer units, as observed by other authors. ${ }^{[35]}$ Films containing lecithin exhibited greater weight loss in the second stage, which can be attributed to the gradual decomposition of lecithin (about $20 \%$ weight loss at $270^{\circ} \mathrm{C}$ ) as deduced from the TGA of pure lecithin. The boiling point of eugenol is $253^{\circ} \mathrm{C},{ }^{[39]}$ which implies that when Eu or CLEO are 
present in the film, their thermal release would overlap with the polymer's degradation temperature range.

Table 6 shows the onset temperature $\left(T_{0}\right)$ and maximum degradation rate temperature $\left(T_{\max }\right)$ of the polymer for the different films. The onset and $T_{\max }$ temperature values of polymer decomposition were hardly affected by the lipid presence, which indicates that no strong interactions occurred among lipid molecules and polymer chains. Nevertheless, the thermal degradation of lipid components affected the thermogram shape. The films with free eugenol or CLEO had the highest onset temperature and degradation rate of the polymer, which could indicate that the eugenol remaining in the film may be strongly bonded to the polymer chains, thus affecting their thermal behavior. In this sense, its extraction could be limited, this contributing to the very low retention determined, as previously comented.

\subsection{Antimicrobial activity}

Table 7 and 8 show E. coli and L. innocua counts, respectively, immediately after the inoculation of the bacterial culture ( 0 days) and after 6 days of cold storage. Microbial counts were significantly reduced by film application right after the inoculation. The higher antibacterial effect (lower bacterial counts) was obtained for $E$. coli, which is in agreement with the greatest antimicrobial effect of chitosan against Gram - negative bacteria ${ }^{40}$, as compared to Gram -positive bacteria such as $L$ innocua. In the liquid medium, the application of films containing the active compound led to no bacterial growth during the whole period of cold storage, for both E. coli and L. Innocua. This can be explained by the solution of the film matrix and the rapid release of the active compound. In 
the agar plates, immediately after inoculation, samples coated with films containing eugenol or cinnamon leaf essential oil led to a signficant reduction in the growth of both bacteria as compared to those non-coated (control) and those coated with $\mathrm{CH}$ or $\mathrm{CH} / \mathrm{Lec}$. In samples coated with films containg the active compouns no growth was detected at the end of the storage period.

\section{Conclusions}

The incorporation of lecithin liposomes containing eugenol or cinnamon leaf essential oil into chitosan films obtained by casting allowed for a high retention ratio $(40-50 \%)$ of volatile compounds, as compared to the $1-2 \%$ which is retained when they are free incorporated by emulsification. Films with liposomes exhibited a lamellar microstructure where lipid lecithin layers seem to alternate with polymer layers, due to the liposome phase transitions during the progressive film drying. This microstructure improved the extensibility of the films, while reducing their firmness and water vapor permeability. Liposome incorporation modified the optical properties of the films; the gloss was reduced, chrome was increased and the films became reddish, coherently with the chromatic properties of lecithin. The addition of the active compounds enhanced the antimicrobial activity of pure chitosan films for both, free or lecithin encapsulated form. Encapsulation did not affect the effective release of actives to exert the antimicrobial effect. Therefore, the encapsulation of volatile active compounds in liposomes emerges as a good strategy for the obtention of active films with essential oils.

\section{Acknowledgements}


The authors acknowledge the financial support provided by the Ministerio de Economía y Competitividad (Project AGL2013-42989-R). Cristina Valencia Sullca thanks the Programa Nacional de Becas del Perú (Pronabec) for the completion of her doctoral thesis.

\section{References}

1. Jiménez A, Fabra MJ, Talens P and Chiralt A, J. Food Eng. 116(3): 695702 (2013).

http://dx.doi.org/10.1016/j.jfoodeng.2013.01.010

2. Zhai M, Zhao L, Yoshii F and Kume T, Carbohydr. Polym. 57(1): 83-88 (2004).

http://dx.doi.org/10.1016/j.carbpol.2004.04.003

3. Perdones Á, Vargas M, Atarés L and Chiralt A, Food Hydrocolloids 36: 256-264 (2014).

http://dx.doi.org/10.1016/j.foodhyd.2013.10.003

4. Singh G, Maurya S, de Lampasona MP and Catalan CAN, Food Chem. Toxicol. 45: 1650-1661 (2007).

doi: $10.1016 /$ j.fct.2007.02.031

5. De Martino L, De Feo V, Fratianni F and Nazzaro F, Natural Product Communications 4: 1741-1750 (2009).

ISSN 1934-578X

6. Bajpai VK, Baek KH and Kang SC, Food Res. Int. 45, 722-734 (2012). doi: $10.1016 /$ j.foodres.2011.04.052

7. Shah B, Davidson M and Zhong Q, Int. J. Food Microbiol. 161: 53-59 (2013).

http://dx.doi.org/10.1016/j.ijfoodmicro.2012.11.020 
8. FDA, US Food and Drug Administration. Code of Federal Regulations, Title 21-Food and Drugs, Part 172, Subpart F, Section 172.515 (2009).

9. Sebaaly C, Jraij A, Fessi H, Charcosset C and Greige-Gerges H, Food Chem. 178: 52-62 (2015).

http://dx.doi.org/10.1016/j.foodchem.2015.01.067

10. Atares L and Chiralt A, Trends Food Sci Technol. 48: 51-62 (2016). doi:10.1016/j.tifs.2015.12.001

11. Sánchez-González L, Chiralt A, González-Martínez C and Cháfer M, J. Food Eng. 105(2): 246-253 (2011).

http://dx.doi.org/10.1016/j.jfoodeng.2011.02.028

12. Bakkali F, Averbeck S, Averbeck D and Idaomar M, Food Chem. Toxicol. 46(2): 446-475 (2008).

http://dx.doi.org/10.1016/j.fct.2007.09.106

13. Wu J, Liu H, Ge S, Wang S, Qin Z, Chen L, Zheng Q, Liu Q and Zhang Q, Food Hydrocolloids 43: 427-435 (2015).

http://dx.doi.org/10.1016/j.foodhyd.2014.06.017

14. Imran M, Revol-Junelles AM, René N, Jamshidian M, Akhtar MJ, ArabTehrany E and Desobry S, Food Hydrocolloids 29(2): 407-419 (2012). http://dx.doi.org/10.1016/j.foodhyd.2012.04.010

15. Zhang HY, Tehrany EA, Kahn CJF, Ponçot M, Linder M and Cleymand F, Carbohydr. Polym. 88: 618-627 (2012). http://dx.doi.org/10.1016/j.carbpol.2012.01.007

16. Jiménez A, Sánchez-González L, Desobry S, Chiralt A and Tehrany EA, Food Hydrocolloids 35: 159-169 (2014). http://dx.doi.org/10.1016/j.foodhyd.2013.05.006

17. Olasupo NA, Fitzgerald DJ, Gasson MJ and Narbad A, Lett. Appl. Microbiol. 37: 448-451(2003). 
18. Alma HM, Ertas M, Nitz $S$ and Kollmannsberger $H$, BioResources 2(2):265-269 (2007).

ISSN: $1930-2126$

19. ASTM, Standard test method for tensile properties of thin plastic sheeting, Standard D882, In Annual book of American standard testing methods, Philadelphia, PA: American Society for Testing and Materials, pp. 162-170 (2001).

\section{View Record in Scopus}

20. ASTM, Standard test methods for water vapour transmission of materials, Standard designations: E96-95 Annual book of ASTM standards, Philadelphia, PA: American Society for Testing and Materials, pp. 406-413 (1995).

\section{View Record in Scopus}

21. Mc Hugh TH, Avena-Bustillos R and Krochta JM, J. Food Sci. 58(4): 899903 (1993).

http://dx.doi.org/10.1111/j.1365-2621.1993.tb09387.x

22. Judd DB and Wyszecki G. Colour in business, science and industry, $3^{\text {rd }}$ edition, New York, NY: John Wiley and Sons, Inc., ISBN 0471452122 (1975).

23. Hutchings JB, Food and colour appearance, $2^{\text {nd }}$ edition, Gaithersburg, MD: Chapman and Hall Food Science Book, Aspen Publication (1999). ISBN: 978-1-4613-6007-0 (Print) 978-1-4615-2373-4 (Online) http://dx.doi.org/10.1007/978-1-4615-2373-4

24. ASTM, Standard test method for specular gloss, In Designation (D523), Annual book of ASTM standards, Vol. 06.01, Philadelphia, PA: American Society for Testing and Materials (1999). 
25. Falguera V, Quintero JP, Jiménez A, Muñoz JA and Ibarz A, Trends Food Sci. Technol. 22(6): 292-303 (2011).

http://dx.doi.org/10.1016/j.tifs.2011.02.004

26. Leceta I, Guerrero P and De la Caba K, Carbohydr. Polym. 93(1): 339346 (2013).

http://dx.doi.org/10.1016/j.carbpol.2012.04.031

27. Krog NJ, Food emulsifiers and their chemical and physical properties, In Larsson EDK and Friberg SE (Eds.), Food emulsions. New York and Basel: Marcel Dekker, Inc., pp.127-180 (1990).

28. Larsson $\mathrm{K}$ and Dejmek $\mathrm{P}$, Crystal and liquid crystal structures of lipids, In Larsson EDK and Friberg SE (Eds.), Food emulsions. New York and Basel: Marcel Dekker, Inc., pp.97-125 (1990).

29. Pérez-Gago MB and Krochta JM, J Agric Food Chem. 49: 996-1002 (2001).

http://dx.doi.org/10.1021/jf000615f

30. Fabra MJ, Talens P and Chiralt A, J. Food Eng. 85(3): 393-400 (2008). http://dx.doi.org/10.1016/j.jfoodeng.2007.07.022

31. Sánchez-González L, Vargas M, González-Martínez C, Chiralt A and Cháfer M, Food Hydrocolloids 23(8): 2102-2109 (2009). http://dx.doi.org/10.1016/j.foodhyd.2009.05.006

32. Mc Hugh TH and Krochta JM, J. Am. Oil Chem. Soc. 71(3): 307-312 (1994).

http://dx.doi.org/10.1007/BF02638058

33. Ma X, Chang PR and Yu J, Carbohydr. Polym. 72(3): 369-375 (2008). http://dx.doi.org/10.1016/j.carbpol.2007.09.002

34. Fabra MJ, Talens P and Chiralt A, Food Hydrocolloids 24(4): 384391(2010). 
http://dx.doi.org/10.1016/j.foodhyd.2009.11.004

35. Shen Z and Kamdem DP, Int. J. Biol. Macromol. 74: 289-296 (2015).

http://dx.doi.org/10.1016/j.ijbiomac.2014.11.046

36. Ojagh SM, Rezaei M, Razavi SH and Hashem SM, Food Chem. 122:161-166 (2010).

doi:10.1016/j.foodchem.2010.02.033

37. Fabra MJ, Talens P and Chiralt A, Food Hydrocolloids 23(3): 676-683 (2009).

http://dx.doi.org/10.1016/j.foodhyd.2008.04.015

38. Cano A, Jiménez A, Cháfer M, Gónzalez C and Chiralt A, Carbohydr. Polym. 111: 543-555 (2014).

http://dx.doi.org/10.1016/j.carbpol.2014.04.075

39. Van Roon A, Parsons JR and Govers HAJ, J. Chromatogr. A. 955: 105115 (2002).

http://dx.doi.org/10.1016/S0021-9673(02)00200-5

40. Devlieghere, A. Vermeulen and J. Debevere, Food Microbiology. 21: 703-714 (2004).

http://dx.doi.org/10.1016/i.fm.2004.02.008 
Figures

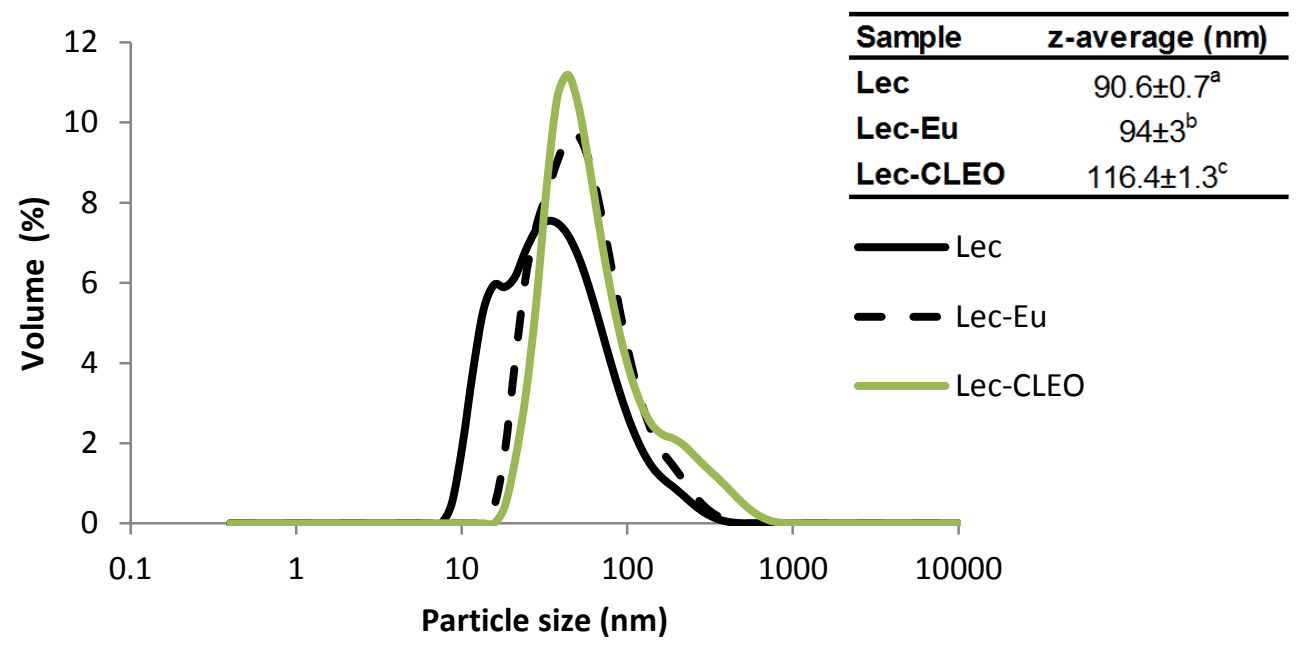

Figure 1. Typical particle size distribution curves of the nanoliposome dispersions Lec: lecithin, Eu: eugenol, CLEO: cinnamon leaf essential oil. 


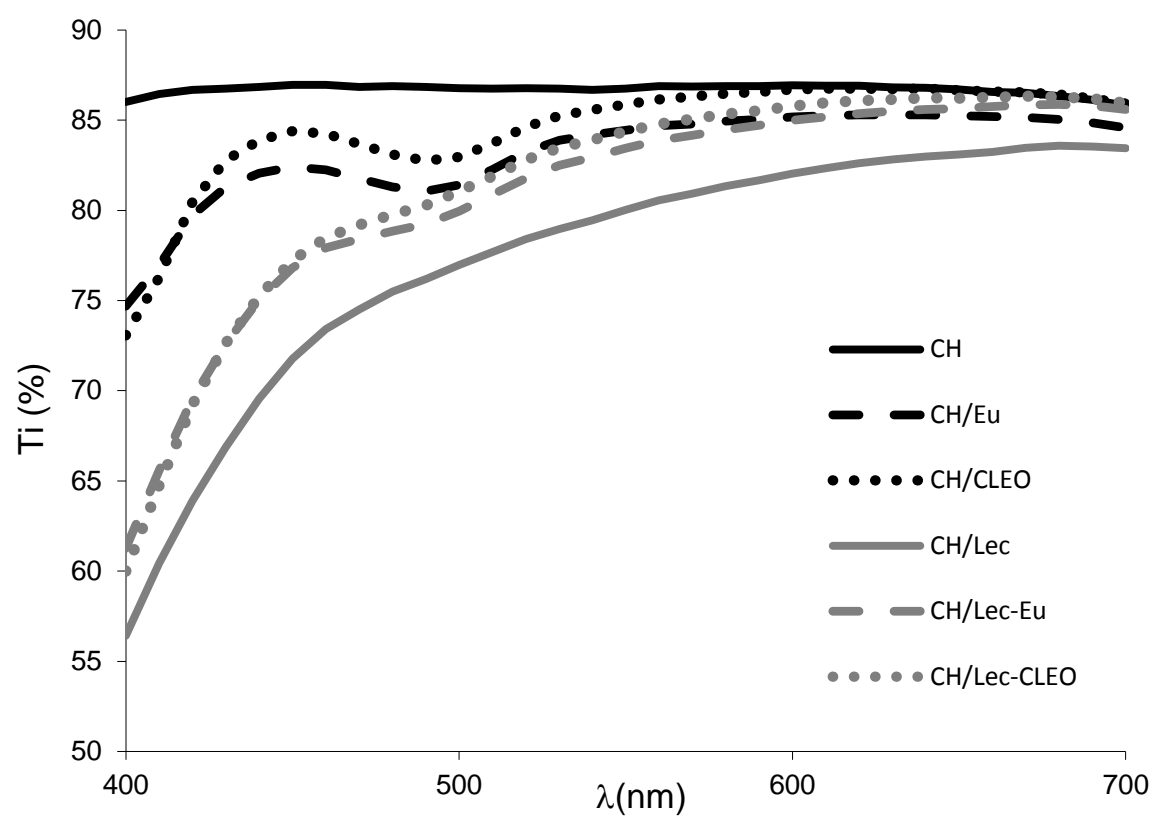

Figure 2. Spectral distribution curves of internal transmittance (Ti) of the films. Lec: lecithin, Eu: eugenol, CLEO: cinnamon leaf essential oil, $\mathrm{CH}$ : chitosan. 


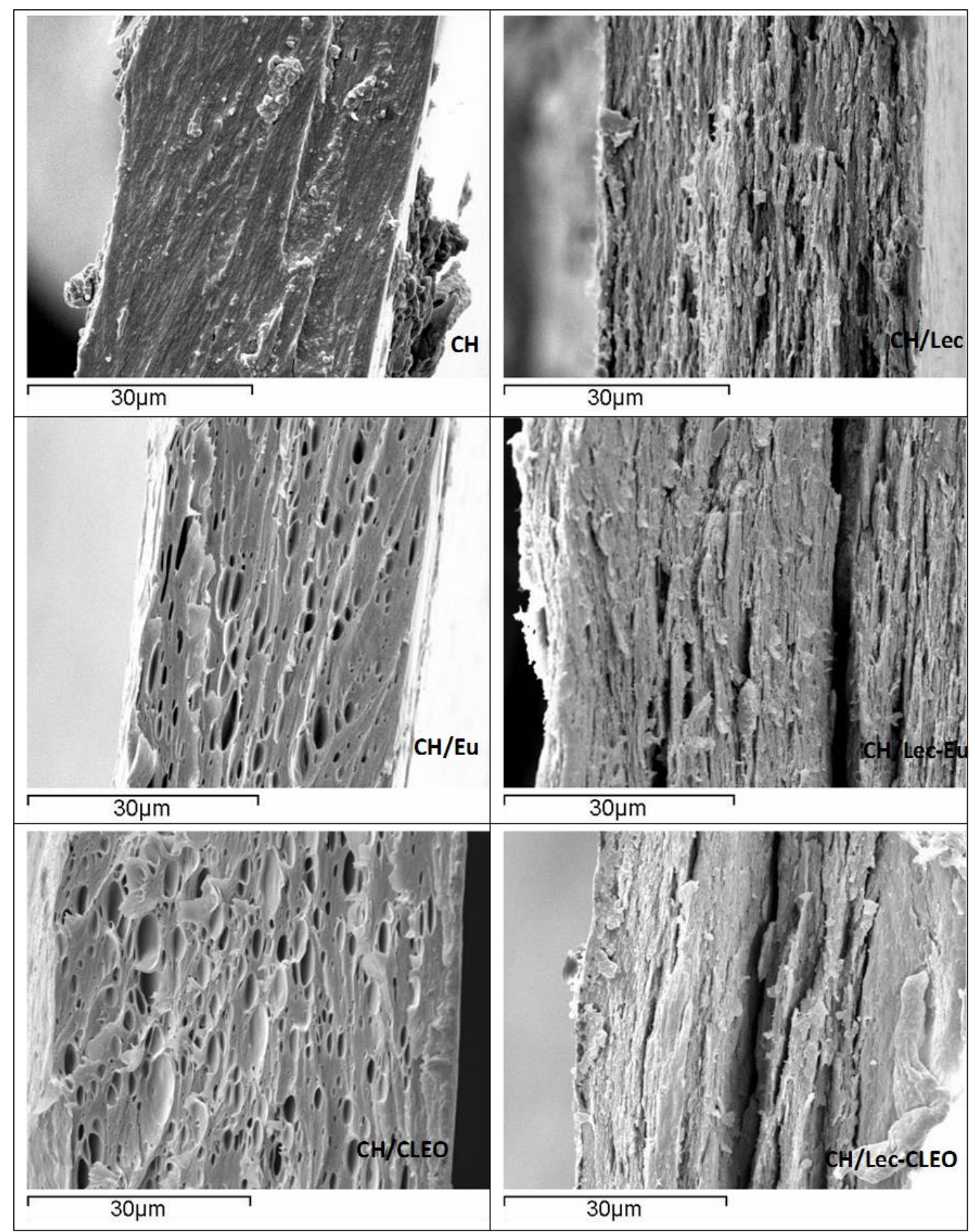

Figure 3: SEM micrographs of the cross section of the chitosan films with and without eugenol and cinnamon leaf essential oil in free form (left) or lecithin liposomes (right). Lec: lecithin, Eu: eugenol, CLEO: cinnamon leaf essential oil, $\mathrm{CH}$ : chitosan. 


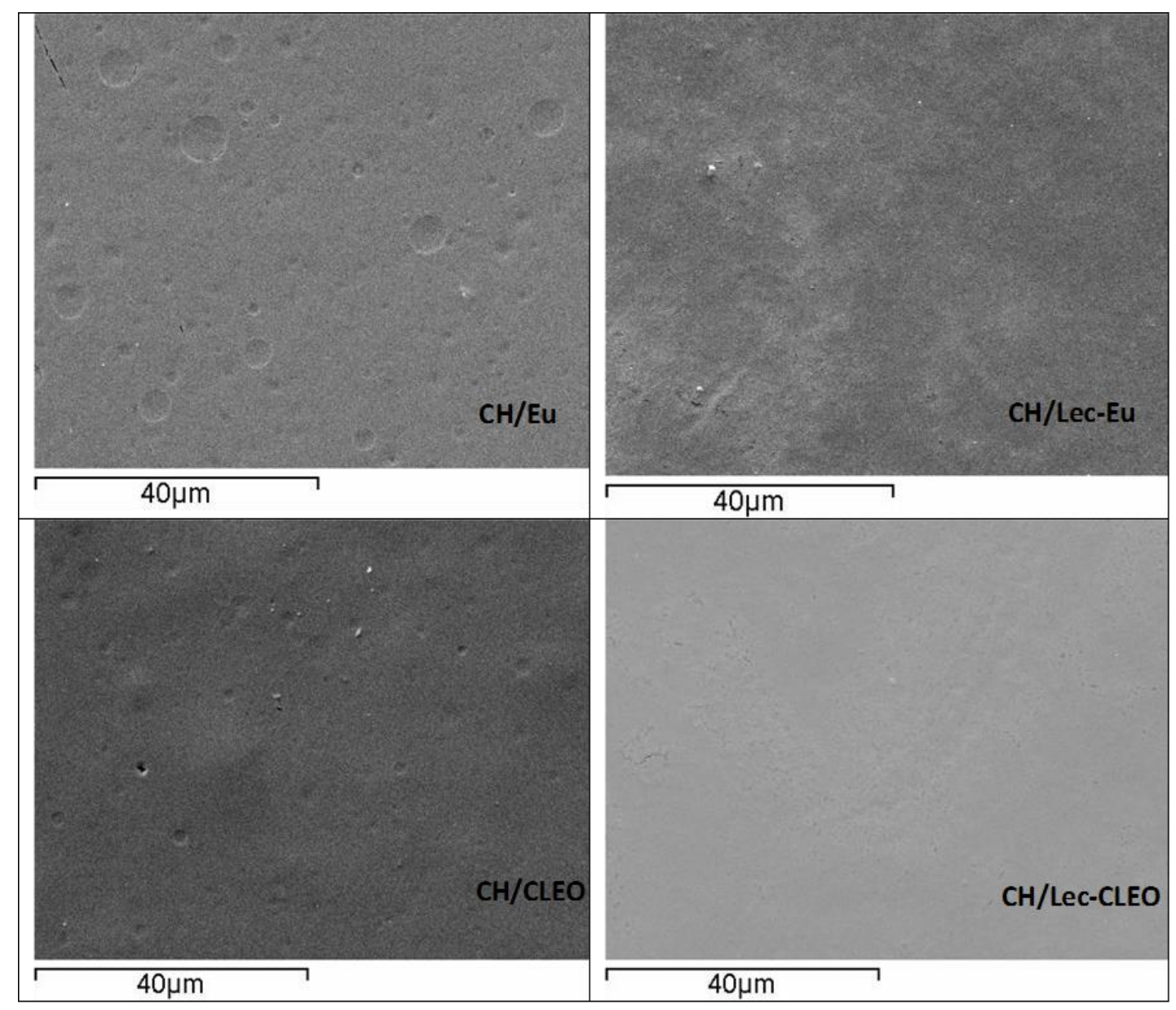

Figure 4: SEM micrographs of the surface of the chitosan films with eugenol (top) and cinnamon leaf essential oil (bottom) in free form (left) or lecithin liposomes (right). Lec: lecithin, Eu: eugenol, CLEO: cinnamon leaf essential oil, $\mathrm{CH}$ : chitosan. 

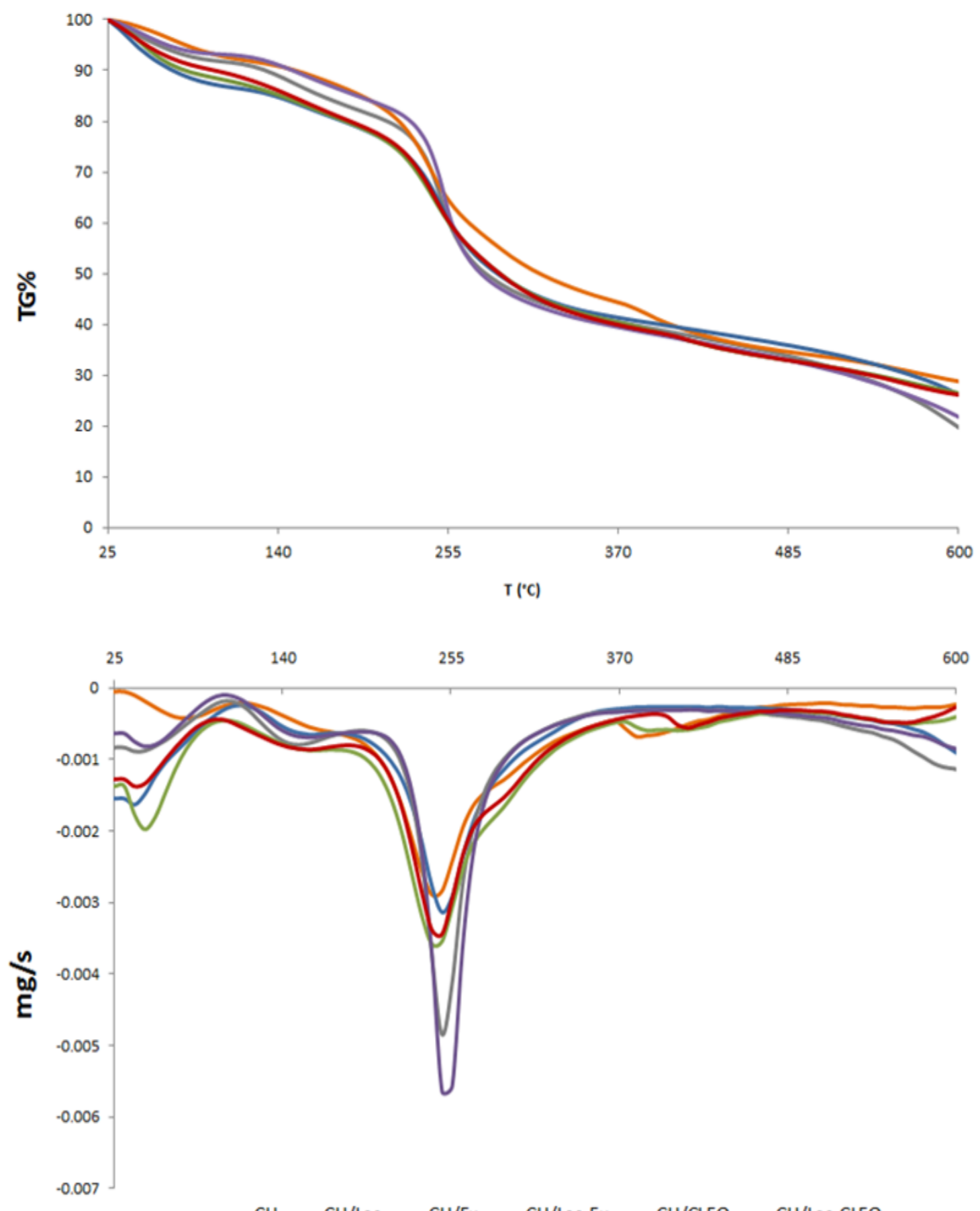

$-\mathrm{CH}-\mathrm{CH} / \mathrm{Lec}-\mathrm{CH} / \mathrm{Eu}-\mathrm{CH} /$ Lec-Eu $-\mathrm{CH} / \mathrm{ClEO}-\mathrm{CH} /$ Lec-CLEO

Figure 5. First derivative of weight loss vs. temperature curves obtained from TGA. Lec: lecithin, Eu: eugenol, CLEO: cinnamon leaf essential oil, $\mathrm{CH}$ : chitosan. 
Table 1. Density and $\zeta$-potential of nanoliposome dispersions (ND) and filmforming dispersions (FFD). Mean values and standard deviation. Lec: lecithin, Eu: eugenol, CLEO: cinnamon leaf essential oil, $\mathrm{CH}$ : chitosan.

\begin{tabular}{lcc}
\hline ND & $\boldsymbol{\rho}\left(\mathbf{k g} / \mathbf{m}^{3}\right)$ & $\begin{array}{c}\boldsymbol{\zeta} \text { - Potencial } \\
(\mathbf{m V})\end{array}$ \\
\hline Lec & $1007 \pm 2^{\mathrm{a}}$ & $-35.1 \pm 1.6^{\mathrm{c}}$ \\
Lec-Eu & $1009 \pm 1^{\mathrm{a}}$ & $-43.0 \pm 0.7^{\mathrm{a}}$ \\
Lec-CLEO & $1009 \pm 2^{\mathrm{a}}$ & $-41.4 \pm 0.5^{\mathrm{b}}$ \\
\hline FFD & $\boldsymbol{\rho}\left(\mathbf{k g} / \mathbf{m}^{3}\right)$ & $\boldsymbol{\zeta}(\mathbf{m V})$ \\
\hline CH & $1004 \pm 3^{\mathrm{a}}$ & $30.3 \pm 1.4^{\mathrm{a}}$ \\
CH/Eu & $1006 \pm 1^{\mathrm{a}}$ & $43 \pm 3^{\mathrm{b}}$ \\
CH/CLEO & $1006 \pm 1^{\mathrm{a}}$ & $57 \pm 2^{\mathrm{c}}$ \\
CH/Lec & $1018 \pm 2^{\mathrm{b}}$ & $65 \pm 3^{\mathrm{d}}$ \\
CH/Lec-Eu & $1005 \pm 1^{\mathrm{a}}$ & $66.4 \pm 0.3^{\mathrm{d}}$ \\
CH/Lec-CLEO & $1005 \pm 1^{\mathrm{a}}$ & $67.3 \pm 0.5^{\mathrm{d}}$ \\
\hline
\end{tabular}

Different superscript letters $(a, b, c, d)$ within the same column indicate significant differences among formulations $(p<0.05)$. 
Table 2. Mass fraction of eugenol in the dried films ( $\mathrm{mg} / \mathrm{g}$ film solids), extracted in the dried film and initially incorporated, and percentage retention (extracted with respect to the initially added). Lec: lecithin, Eu: eugenol, CLEO: cinnamon leaf essential oil, $\mathrm{CH}$ : chitosan.

\begin{tabular}{lccc}
\hline Film & Extracted & Incorporated & \% Retention \\
\hline CH/Eu & $4.9 \pm 1.0^{\mathrm{b}}$ & 357 & 1 \\
CH/Lec-Eu & $108.9 \pm 1.3^{\mathrm{c}}$ & 263 & 41 \\
CH/CLEO & $5.4 \pm 1.3^{\mathrm{d}}$ & 318 & 2 \\
CH/LeC-CLEO & $118 \pm 3^{\mathrm{e}}$ & 234 & 51 \\
\hline
\end{tabular}

Different superscript letters $(a, b, c)$ within the same column indicate significant differences among formulations $(p<0.05)$. 
Table 3. Thickness and tensile parameters (elastic modulus, EM; tensile strength, TS; percentage elongation, \%E) of the films. Mean values and standard deviation. Lec: lecithin, Eu: eugenol, CLEO: cinnamon leaf essential oil, $\mathrm{CH}$ : chitosan.

\begin{tabular}{lccll}
\hline Film & $\begin{array}{c}\text { Thickness } \\
(\boldsymbol{\mu m})\end{array}$ & EM $(\mathrm{MPa})$ & TS $(\mathrm{MPa})$ & $\% \mathrm{E}$ \\
\hline $\mathbf{C H}$ & $43 \pm 2^{\mathrm{b}}$ & $1660 \pm 170^{\mathrm{d}}$ & $53 \pm 4^{\mathrm{b}}$ & $6 \pm 1^{\mathrm{a}}$ \\
$\mathbf{C H} / \mathrm{Eu}$ & $33 \pm 2^{\mathrm{a}}$ & $1623 \pm 70^{\mathrm{d}}$ & $46 \pm 4^{\mathrm{ab}}$ & $8 \pm 3^{\mathrm{a}}$ \\
$\mathrm{CH} /$ CLEO & $35 \pm 2^{\mathrm{a}}$ & $1460 \pm 30^{\mathrm{c}}$ & $42 \pm 3^{\mathrm{a}}$ & $7 \pm 4^{\mathrm{a}}$ \\
$\mathbf{C H} /$ LeC & $45 \pm 1^{\mathrm{b}}$ & $1145 \pm 4^{\mathrm{b}}$ & $41 \pm 1^{\mathrm{a}}$ & $11 \pm 3^{\mathrm{a}}$ \\
CH/LeC-Eu & $48 \pm 2^{\mathrm{c}}$ & $840 \pm 80^{\mathrm{a}}$ & $51 \pm 10^{\mathrm{b}}$ & $31 \pm 8^{\mathrm{b}}$ \\
CH/Lec-CLEO & $49 \pm 2^{\mathrm{c}}$ & $860 \pm 70^{\mathrm{a}}$ & $43 \pm 3^{\mathrm{a}}$ & $27 \pm 4^{\mathrm{b}}$ \\
\hline
\end{tabular}

Different superscript letters $(a, b, c)$ within the same column indicate significant differences among formulations $(p<0.05)$. 
Table 4. Water content $\left(X_{w}\right)$, water vapor permeability (WVP) and solubility ( $g$ of solubilized solids $/ 100 \mathrm{~g}$ of initial solids) of the films. Mean values and standard deviation. Lec: lecithin, Eu: eugenol, CLEO: cinnamon leaf essential oil, $\mathrm{CH}$ : chitosan.

\begin{tabular}{|c|c|c|c|}
\hline Film & $\begin{array}{c}\text { Xw (g water/ } \\
100 \text { g dry film) }\end{array}$ & $\begin{array}{c}\text { WVP } \\
\left(\mathrm{g} \cdot \mathrm{mm} \cdot \mathrm{kPa}^{-1} \cdot \mathrm{h}^{-1} \cdot \mathrm{m}^{2}\right)\end{array}$ & Solubility (\%) \\
\hline $\mathrm{CH}$ & $39 \pm 2^{f}$ & $4.3 \pm 0.2^{d}$ & $67 \pm 2^{d}$ \\
\hline $\mathrm{CH} / \mathrm{Eu}$ & $25.4 \pm 0.8^{\mathrm{ab}}$ & $3.7 \pm 0.2^{c}$ & $43 \pm 1^{c}$ \\
\hline CH/CLEO & $25.6 \pm 1.2^{\mathrm{ab}}$ & $4.6 \pm 0.4^{e}$ & $40 \pm 1^{b c}$ \\
\hline $\mathrm{CH} / \mathrm{Lec}$ & $30.1 \pm 1.7^{d}$ & $2.4 \pm 0.2^{b}$ & $40 \pm 2^{b}$ \\
\hline CH/Lec-Eu & $24.2 \pm 0.6^{a}$ & $2.2 \pm 0.2^{\mathrm{a}}$ & $37 \pm 2^{a}$ \\
\hline CH/LeC-CLEO & $26.9 \pm 0.8^{\mathrm{cd}}$ & $1.90 \pm 0.2^{\mathrm{a}}$ & $35 \pm 1^{a}$ \\
\hline
\end{tabular}

Different superscript letters $(a, b, c, d)$ within the same column indicate significant differences among formulations $(p<0.05)$. 
Table 5. Lightness $\left(\mathrm{L}^{*}\right)$, chroma $\left(\mathrm{C}^{*} \mathrm{ab}\right)$, hue $\left(\mathrm{h}^{*} \mathrm{ab}\right)$ and gloss $\left(60^{\circ}\right)$ of the films. Mean values and standard deviation. Lec: lecithin, Eu: eugenol, CLEO: cinnamon leaf essential oil, $\mathrm{CH}$ : chitosan.

\begin{tabular}{|c|c|c|c|c|}
\hline Film & $L^{*}$ & $\mathbf{C}^{\star}{ }_{a b}$ & $\mathbf{h}^{*}{ }^{a b}$ & Gloss $\left(60^{\circ}\right)$ \\
\hline $\mathrm{CH}$ & $91 \pm 2^{e}$ & $4 \pm 2^{a}$ & $109 \pm 5^{c}$ & $51 \pm 6^{d}$ \\
\hline $\mathrm{CH} / \mathrm{Eu}$ & $75 \pm 4^{\text {cd }}$ & $14 \pm 6^{b}$ & $66 \pm 6^{a}$ & $19 \pm 2^{b}$ \\
\hline CH/CLEO & $77.3 \pm 1.3^{\mathrm{d}}$ & $15.0 \pm 1.3^{b}$ & $66 \pm 2^{\mathrm{a}}$ & $15 \pm 3^{a}$ \\
\hline $\mathrm{CH} / \mathrm{Lec}$ & $67.4 \pm 1.1^{\mathrm{a}}$ & $23.0 \pm 0.2^{c}$ & $80.4 \pm 0.7^{c}$ & $33 \pm 2^{c}$ \\
\hline CH/Lec-Eu & $69.6 \pm 1.1^{\mathrm{ab}}$ & $23.0 \pm 0.3^{c}$ & $78.4 \pm 0.3^{c}$ & $15 \pm 2^{\mathrm{a}}$ \\
\hline $\mathrm{CH} /$ Lec-CLEO & $72.0 \pm 0.3^{\mathrm{bc}}$ & $26.3 \pm 0.4^{c}$ & $80.0 \pm 0.2^{c}$ & $20 \pm 3^{b}$ \\
\hline
\end{tabular}

Different superscript letters $(a, b, c, d)$ within the same column indicate significant differences among formulations $(p<0.05)$. 
Table 6. Onset temperature $\left(T_{0}\right)$ and maximum degradation rate temperure of the films. Mean values and standard deviation. Lec: lecithin, Eu: eugenol, CLEO: cinnamon leaf essential oil, $\mathrm{CH}$ : chitosan.

\begin{tabular}{lcc}
\hline Film & $\mathbf{T}_{0}\left({ }^{\circ} \mathbf{C}\right)$ & $\mathbf{T}_{\max }\left({ }^{\circ} \mathbf{C}\right)$ \\
\hline CH & $193 \pm 4^{\mathrm{a}}$ & $248 \pm 3^{\mathrm{a}}$ \\
CH/Eu & $214 \pm 3^{\mathrm{b}}$ & $249 \pm 2^{\mathrm{a}}$ \\
$\mathrm{CH} /$ CLEO & $212 \pm 3^{\mathrm{b}}$ & $248 \pm 6^{\mathrm{a}}$ \\
$\mathrm{CH} /$ Lec & $193 \pm 2^{\mathrm{a}}$ & $243 \pm 2^{\mathrm{a}}$ \\
CH/Lec-Eu & $193 \pm 4^{\mathrm{a}}$ & $245 \pm 2^{\mathrm{a}}$ \\
CH/LeC-CLEO & $195 \pm 5^{\mathrm{a}}$ & $247 \pm 2^{\mathrm{a}}$ \\
\hline
\end{tabular}

Different superscript letters (a, b, c) within the same column indicate significant differences among formulations $(p<0.05)$. 
Table 7. Escherichia coli counts in liquid (TSA Broth) and solid media (TSA Agar) at $10^{\circ} \mathrm{C}$. Mean values \pm standard deviation Lec: lecithin, Eu: eugenol, CLEO: cinnamon leaf essential oil, $\mathrm{CH}$ : chitosan. ng: no growth

\begin{tabular}{lcccc}
\hline \multirow{2}{*}{ Film } & \multicolumn{4}{c}{ Escherichia coli (log cfu/g) } \\
\cline { 2 - 5 } & \multicolumn{2}{c}{ Broth } & \multicolumn{2}{c}{ Agar } \\
\cline { 2 - 5 } & $\mathbf{0}$ days & $\mathbf{6}$ days & 0 days & $\mathbf{6}$ days \\
\hline Control & $5.7 \pm 0.3^{\text {ax }}$ & $8.15 \pm 0.03^{\text {ay }}$ & $5.58 \pm 0.07^{\text {ax }}$ & $6.69 \pm 0.07^{\text {ay }}$ \\
CH & $2.7 \pm 0.3^{\text {bx }}$ & $2.16 \pm 0.02^{\text {by }}$ & $3.63 \pm 0.03^{\mathrm{b}}$ & $4.02 \pm 0.04^{\mathrm{b}}$ \\
CH/Eu & $\mathrm{ng}$ & $\mathrm{ng}$ & $2.56 \pm 0.08^{\mathrm{c}}$ & $\mathrm{ng}$ \\
$\mathrm{CH} /$ CLEO & $\mathrm{ng}$ & $\mathrm{ng}$ & $2.55 \pm 0.06^{\mathrm{c}}$ & $\mathrm{ng}$ \\
CH/Lec & $2.95 \pm 0.04^{\mathrm{bx}}$ & $2.07 \pm 0.02^{\mathrm{by}}$ & $3.92 \pm 0.02^{\mathrm{b}}$ & $3.92 \pm 0.04^{\mathrm{b}}$ \\
CH/LeC-Eu & $\mathrm{ng}$ & $\mathrm{ng}$ & $2.70 \pm 0.08^{\mathrm{c}}$ & $\mathrm{ng}$ \\
CH/LeC-CLEO & $\mathrm{ng}$ & $\mathrm{ng}$ & $2.74 \pm 0.03^{\mathrm{c}}$ & $\mathrm{ng}$ \\
\hline
\end{tabular}

Different superscript letters (a, b, c) within the same column indicate significant differences among formulations ( $p<0.05)$.

Different superscript letters $(x, y)$ within the same column indicate significant differences due to storage time. 
Table 8. Listeria innocua counts in liquid (TSA Broth) and solid media (TSA Agar). Mean values \pm standard deviation Lec: lecithin, Eu: eugenol, CLEO: cinnamon leaf essential oil, $\mathrm{CH}$ : chitosan. ng: no growth

\begin{tabular}{lcccc}
\hline \multirow{2}{*}{ Film } & \multicolumn{4}{c}{ Listeria innocua (log cfu/g) } \\
\cline { 2 - 5 } & \multicolumn{2}{c}{ Broth } & \multicolumn{2}{c}{ Agar } \\
\cline { 2 - 5 } & 0 days & 6 days & 0 days & 6 days \\
\hline Control & $5.40 \pm 0.02^{\text {ax }}$ & $7.81 \pm 0.03^{\text {ay }}$ & $5.38 \pm 0.07^{\text {ax }}$ & $7.04 \pm 0.01^{\text {ay }}$ \\
CH & $4.44 \pm 0.03^{\text {bx }}$ & ng & $4.16 \pm 0.01^{\mathrm{b}}$ & $4.20 \pm 0.02^{\mathrm{b}}$ \\
CH/Eu & ng & ng & $2.83 \pm 0.05^{\mathrm{c}}$ & $\mathrm{ng}$ \\
CH/CLEO & $\mathrm{ng}$ & $\mathrm{ng}$ & $2.89 \pm 0.04^{\mathrm{c}}$ & $\mathrm{ng}$ \\
CH/Lec & $4.46 \pm 0.02^{\mathrm{by}}$ & $\mathrm{ng}$ & $4.28 \pm 0.02^{\mathrm{b}}$ & $4.32 \pm 0.01^{\mathrm{b}}$ \\
CH/Lec-Eu & $\mathrm{ng}$ & $\mathrm{ng}$ & $2.97 \pm 0.05^{\mathrm{c}}$ & $\mathrm{ng}$ \\
CH/Lec-CLEO & $\mathrm{ng}$ & $\mathrm{ng}$ & $2.97 \pm 0.03^{\mathrm{c}}$ & $\mathrm{ng}$ \\
\hline
\end{tabular}

Different superscript letters $(a, b, c)$ within the same column indicate significant differences among formulations ( $p<0.05)$.

Different superscript letters $(x, y)$ within the same column indicate significant differences due to storage time 